\title{
Mid-Term Outcomes of Percutaneous Treatment of Superficial Femoral Artery Total Occlusions: Single Center Experience
}

\author{
Ahmet Hakan Ateş ${ }^{1,4, *}$, [MD] \\ ORCID: 0000-0001-5414-7268 \\ Aysu Başak Özbalc1, ${ }^{2, *},[\mathrm{MD}]$ \\ ORCID: 0000-0001-9974-5974 \\ Selim Kul${ }^{3},[\mathrm{MD}]$ \\ ORCID: 0000-0001-8329-4603 \\ Mustafa Yenerçağ ${ }^{4}$, [MD] \\ ORCID: 0000-0002-0933-7852 \\ Metin Okşul', [MD] \\ ORCID: 0000-0002-4759-4868
}

Uğur Arslan ${ }^{4},[\mathrm{MD}]$

\section{ORCID: 0000-0001-8572-3571}

${ }^{1}$ Department of Cardiology, Hacettepe University Faculty of Medicine, Ankara, Turkey.

${ }^{2}$ Department of Radiology, Health Sciences University Samsun Training and Research Hospital, Samsun, Turkey.

${ }^{3}$ Department of Cardiology, Health Sciences University Ahi Evren Training and Research Hospital, Trabzon, Turkey

${ }^{4}$ Department of Cardiology, Health Sciences University Samsun Training and Research Hospital, Samsun, Turkey

Corresponding Author: Ahmet Hakan Ateş Department of Cardiology, Hacettepe University Faculty of Medicine, Ankara, Turkey.

Phone: +90 5056818961

E-mail: ahmethakanates@yahoo.com

Received: 21 June 2019, Accepted:30 December 2019,

Published online: 31 December 2019

\section{wa ABTRACT Cem}

Objectives: Superficial femoral artery is the most commonly effected vessel in peripheral arterial disease and superficial femoral artery total occlusions constitute the 50\% of peripheral arterial disease patients presenting with symptoms. In this study, we investigated our patients with superficial femoral artery total occlusions who were treated with percutaneous treatment strategy.

Materials and Methods: In this study, we included ambulatory patients who were admitted to our clinics due to symptomatic severe superficial femoral artery total occlusion and underwent percutaneous transluminal angioplasty or underwent percutaneous transluminal angioplasty + stenting procedure. The demographic findings of the patients, procedure details, complications and follow-up results were noted.

Results: Out of 67 patients, 62 (92.5\%) underwent percutaneous transluminal angioplasty or percutaneous transluminal angioplasty + stenting procedure successfully for superficial femoral artery total occlusions. Only one serious complication, acute renal failure resulting in death developed during hospitalization. The mean follow-up time after the procedure was $11.1 \pm 7.2$ months. During this follow-up time 36 (58.1\%) were asymptomatic. Out of 26 patients who were symptomatic, only 6 of them underwent reintervention and 3 were recommended surgical intervention.

Conclusion: Peripheral interventions for superficial femoral artery total occlusions are being performed successfully in experienced centers with low complication rates as the first treatment strategy in peripheral arterial disease. Herein, we have presented our patients who underwent successful percutaneous transluminal angioplasty and/or stenting procedure with high success and low complication rates. Peripheral interventions should be the first choice for superficial femoral artery superficial femoral artery total occlusions in experienced centers.

Key words: Peripheral arterial disease, superficial femoral artery, total occlusion, peripheral percutaneous intervention, clinical outcomes

\section{INTRODUCTION}

Peripheral artery disease (PAD) is defined as the presence of stenotic atherosclerotic lesions of the non-coronary arterial bed. Despite this common definition, PAD is usually referred for the lower extremity arterial disease in clinical practice.

The most common symptom of PAD is intermittent claudication. Besides PAD may be asymptomatic or these patients may present with severe rest pain or critical limb ischemia which can cause gangrenous lesions that result in amputation of the effected extremity [1,2]. Superficial femoral artery (SFA) is the most commonly effected vessel in PAD and SFA total occlusions constitute the $50 \%$ of PAD patients presenting with symptoms [3]. Recently with the improvement of the percutaneous treatment strategies; percutaneous transluminal angioplasty (PTA) and/or stenting became the preferred strategy for the treatment of PAD in eligible patients $[4,5,6]$. In this study, we aimed to investigate the clinical characteristics, procedural results and follow-up of 
symptomatic patients with SFA total occlusions who underwent percutaneous balloon angioplasty and/ or stent implantation in our center.

\section{MATERIALS and METHODS}

In this retrospective study, we included ambulatory patients who were admitted to our clinics between January 2015 and March 2017 due to symptomatic severe SFA total occlusions and underwent PTA or stenting procedures. Symptomatic patients were defined as patients with intermittent claudication, rest leg pain or critical limb ischemia. Rutherford classification was used to grade the symptoms of the patients in our study (Table 1) $[7,8]$.

Selective conventional lower extremity arterial angiography was performed to all of these patients to confirm the total occlusion of SFA. Exclusion criteria was as follows; patients who were unable to take dual antiplatelet therapy (active bleeding, recent intracranial hemorrhage), chronic renal failure, any type of cancer with life expectancy $<1$ year and vasculitis. All of the patients were informed about the details of the procedure and written informed consent were taken from all of the patients.

Table 1. Rutherford Classification

\begin{tabular}{|c|c|c|}
\hline Category & Clinical Findings & $\mathrm{n}=62$ \\
0 & Asymptomatic & 0 \\
1 & Mild Claudication & 0 \\
2 & Moderate Claudication & $30(48.4 \%)$ \\
3 & Severe Claudication & $30(48.4 \%)$ \\
4 & İschemic Rest Pain & $2(3.2 \%)$ \\
5 & Minor Tissue Loss & 0 \\
6 & Major Tissue Loss & 0 \\
\hline
\end{tabular}

Demographic characteristics of the patients were obtained from the hospital records. Hypertension was defined as systolic pressure $>140 \mathrm{~mm} \mathrm{Hg}$ and/ or a diastolic pressure $>90 \mathrm{~mm} \mathrm{Hg}$ or if the patient was taking antihypertensive medications before the admission to our center. The diagnosis of diabetes mellitus (DM) was defined as a previous history of DM treated with drug therapies or patients with $\mathrm{Hba1c}$ concentrations over $6.5 \%$ at admission. Hyperlipidemia was defined as total cholesterol level $>200 \mathrm{mg} / \mathrm{dl}$ or previous history of statin use. Current smokers were defined as those who had smoked for some period during the past year. Coronary artery disease was defined as at least $30 \%$ stenosis in any coronary artery in coronary angiography.

Electrocardiogram, postero-anterior (PA) chest radiography and transthoracic echocardiography were routinely performed to all of the patients. Biochemical tests and complete blood count were also obtained. All of the patients were treated with acetyl salicylic acid (ASA) $300 \mathrm{mg}$ and clopidogrel $600 \mathrm{mg}$ before the procedure and ASA $100 \mathrm{mg}$ daily was continued with clopidogrel $75 \mathrm{mg}$ o.d. thereafter.

Ankle brachial index $(A B I)$ measurement is the first and the easiest diagnostic method in PAD [7]. ABI $<0.9$ is defined as significant for stenosis of peripheric arterial vessel and $A B I<0.4$ refers for critical limb ischemia in PAD patients. Herein, ABI was measured routinely before and after the percutaneous procedure.

In patients whose revascularization is indicated, the decision to proceed with an endovascular approach compared to an open surgical approach is frequently based on the Trans-Atlantic Inter-Society Consensus Document II (TASC II) recommendations [7]. According to the recommendations, TASC-A and B lesions are managed with endovascular techniques in most cases. TASC-C lesions are treated by either bypass or endovascular revascularization based on an individual risk-benefit analysis. Generally, TASC-D lesions are surgically managed. But in some cases, percutaneous techniques can be used for TASC-D lesions. In our study, we also 
defined the lesion types according to the TASC classification [7].

\section{Percutaneous Treatment of SFA Total Occlusions}

Percutaneous procedure was performed either antegradely from contralateral femoral artery with $8 \mathrm{~F}$ sheath or retrogradely from ipsilateral posterior tibial artery using a $6 \mathrm{~F}$ sheath. In the contralateral technique internal mammarian artery (IMA) diagnostic catheter was used for cannulation of contralateral main iliac artery. After cannulation, a 0.035" stiff hydrophilic guidewire was used to introduce 7F long destination sheath. After introduction of destination sheath, $0.035^{\prime \prime}$ hydrophilic guidewire was used with $0.035^{\prime \prime}$ microcatheter support to pass the SFA total occlusion. When the lesion was passed with guidewire, the microcatheter was used to confirm the true lumen of distal vessel. After confirmation of the true lumen, a $0.018^{\prime \prime}$ or $0.035^{\prime \prime}$ stiff guidewire was placed to distal vessel bed and PTA procedure was started with a lower size balloon dilatation. After balloon angioplasty, angiography was performed again and accordingly a drug eluting balloon was applied to the lesions for at least 180 seconds. If optimal result was obtained the procedure was finished. Otherwise in case of flow limiting dissection, rupture or suboptimal results, self-expandable stent implantation was performed.

In case of unsuccessful passage of total occlusion antegradely, retrograde method was applied from ipsilateral posterior tibial artery. A $0.035^{\prime \prime}$ hydrophilic guidewire was used with $0.035^{\prime \prime}$ microcatheter support to pass the SFA total occlusion retrogradely. When the lesion was passed with guidewire, the microcatheter was used to confirm the true lumen of the proximal vessel. After confirmation of the true lumen, a $0.018^{\prime \prime}$ or $0.035^{\prime \prime}$ stiff guidewire was placed to the proximal vessel bed. Similar PTA and stent implantation techniques with the antegrade method were used retrogradely.

Heparin was applied after sheath introduction to all patients. After the procedure, patients were then hospitalized in the intensive care unit for 24 hours.

\section{Follow-Up of Patients}

Routine polyclinic controls were performed to all patients in the first, $3^{\text {th }}, 6^{\text {th }}$ and $12^{\text {th }}$ months. In patients who were symptomatic in the controls, Doppler ultrosonography (DUSG) was performed and in case of suspicion of re-stenosis, computed tomography angiography was obtained. In these visits, the symptoms, $A B I$ and radiologic findings in suitable patients were noted. Repeat angiography and PTA was performed to indicated patients.

\section{Statistical Analysis}

Statistical Package for Social Sciences 16 (SPSS, Chicago, Illinois, USA) was used for statistical analysis. Continuous variables were defined as mean $\pm S D$ and parametric variables were defined as $n(\%)$. Independent samples t-test was used for the continuous variables which were compared between two groups. $p<0.05$ was significant.

\section{RESULTS}

Out of 67 patients, 62 (92.5\%) underwent PTA or PTA + stenting procedure successfully for SFA total occlusions. Among the 5 patients with unsuccessful interventions, 3 had TASC-D and two had TASC-C lesions with heavily calcified total occlusions.

Mean age was $64.9 \pm 7.9$ years. Basal characteristics of the 62 patients are summarized in Table 2 . In Table 1, the symptoms of patients are summarized and accordingly, most of the patients (60(95.2\%)) had moderate to severe claudication.

The angiographic findings can be found in Table 3 . Mean lesion length was $157.5 \pm 65.9 \mathrm{~mm}$. A mean of 2.4 drug eluting balloons were used during the procedure. In patients with suboptimal results (5 (8.1\%)), flow limiting dissection $(10(16.1 \%))$ and arterial rupture (1(1.6\%)) stent implantation was performed in addition to balloon angioplasty in 16 (25.8\%) patients. Except in one patient who was implanted a graft covered stent, all of the stents used were self-expandable. When pre-procedural $A B I$ and post procedural $A B I$ were compared, post-procedural $A B I$ was significantly higher than the pre-procedural $A B I$ $(0.6 \pm 0.2$ vs. $0.9 \pm 0.2 p<0.01)$. 
Table 2. Demographic Findings of Patients $(n=62)$

\begin{tabular}{|c|c|}
\hline Age (years) & $64.9 \pm 7.9$ \\
Sex (male) & $50(80.6 \%)$ \\
Hypertension, $\mathrm{n}(\%)$ & $37(59.7 \%)$ \\
Diabetes Mellitus, $\mathrm{n}(\%)$ & $23(37.1 \%)$ \\
Hyperlipidemia, $\mathrm{n}(\%)$ & $27(43.5 \%)$ \\
Smoking, $\mathrm{n}(\%)$ & $44(71.0 \%)$ \\
Coronary Artery Disease, $\mathrm{n}(\%)$ & $46(74.2 \%)$ \\
Serum Creatinine (mg/dl) & $0.9 \pm 0.3$ \\
LVEF (\%) & $55.5 \pm 9.0$ \\
Hb (gr/dl) & $13.1 \pm 1.8$ \\
LDL (mg/dl) & $124.9 \pm 36.2$ \\
HDL (mg/dl) & $44.9 \pm 14.2$ \\
Cilostazol usage, $\mathrm{n}(\%)$ & $15(24.2 \%)$ \\
Warfarin usage, $\mathrm{n}(\%)$ & $18(29.0 \%)$ \\
Clopidogrel usage, $\mathrm{n}(\%)$ & $21(33.9 \%)$ \\
Rutherford Class & $2.5 \pm 0.6$ \\
Pre-procedure ABI & $0.6 \pm 0.2$ \\
Post-procedure ABI & $0.9 \pm 0.2$ \\
\hline
\end{tabular}

LVEF: Left ventricular ejection fraction, Hb: Hemoglobin, LDL: Low density cholesterol, HDL: High density cholesterol, ABI: Ankle-brachial index

Table 3. Angiographic and Procedural Characteristics of The Patients

\begin{tabular}{|c|c|}
\hline Calcification , n (\%) & $51(82.3 \%)$ \\
\hline Mean Lesion Length (mm) & $157.5 \pm 65.9$ \\
\hline Mean DEB Diameter (mm) & $5.4 \pm 0.5$ \\
\hline Mean Follow -up Time (months) & $11.1 \pm 7.2$ \\
\hline $\begin{array}{l}\text { Only PTA , n (\%) } \\
\text { PTA+Stent, n (\%) }\end{array}$ & $\begin{array}{l}46(74.2 \%) \\
16(25.8 \%)\end{array}$ \\
\hline Lesion type, n (\%) & $\begin{array}{cc}\text { TASC A } & 12(19.4 \%) \\
\text { TASC B } & 22(35.5 \%) \\
\text { TASC C } & 23(37.1 \%) \\
\text { TASC D } & 5(8.1 \%)\end{array}$ \\
\hline Ipsilateral Retrograd, n (\%) & $11(17.7 \%)$ \\
\hline Contralateral Antegrad, n (\%) & $51(82.3 \%)$ \\
\hline Mean Number of Balloons Used & $2.4 \pm 1.0$ \\
\hline
\end{tabular}

Among the major procedural complications, one patient died because of acute renal failure due to contrast nephropathy. She had a TASC-D lesion and approximately $400 \mathrm{cc}$ opaque was used and acute renal failure developed after the procedure. No other serious complication was observed in the hospitalization period. The mean follow-up time after the procedure was 11.1 \pm 7.2 months. The details of follow-up results are summarized in Table 4. During this follow-up time 36 (58.1\%) were asymptomatic, 26 (41.9\%) patients were mild to severely symptomatic. All of the symptomatic patients underwent DUSG examination and only in 11/26 patients, CTA was needed. Among these patients 9/26 needed repeat angiography and re-intervention. Out of 26 patients who were symptomatic, only 6 of them underwent reintervention and 3 were recommended surgical intervention. 
Table 4: Follow-up Results of Patients

\begin{tabular}{|l|c|}
\hline Asymptomatic, $\mathrm{n}(\%)$ & $36(58.1 \%)$ \\
DUSG Performed, $\mathrm{n}(\%)$ & $26(41.9 \%)$ \\
CTA Performed, $\mathrm{n}(\%)$ & $11(17.7 \%)$ \\
Re-angiography, $\mathrm{n}(\%)$ & $9(14.5 \%)$ \\
Re-intervention, $\mathrm{n}(\%)$ & $6(9.7 \%)$ \\
Surgery Needed, $\mathrm{n}(\%)$ & $3(4.8 \%)$ \\
Amputation, $\mathrm{n}(\%)$ & 0 \\
CVA, $\mathrm{n}(\%)$ & None \\
MI, $\mathrm{n}(\%)$ & $2(3.2 \%)$ \\
Death, $\mathrm{n}(\%)$ & $1(1.6 \%)$ \\
\hline DUSG: Doppler ultrasonography, CTA: Computed tomography angiography, CVA: Cerebrovascular accident, Ml: Myocardial \\
infarction
\end{tabular}

\section{DISCUSSION}

PAD is the third leading cause of cardiovascular morbidity after myocardial infarction and stroke. The prevalence of PAD increases with age and according$l y$, there has been a rapid rise in disease recognition as well as treatment $[8,17]$.

In this study, we investigated our patients who underwent PTA and PTA + stenting procedure for SFA total occlusions. The success rate of this procedure was $92.5 \%$ which was comparable with previous studies $[9,10]$. The success rate of peripheral interventions is related with the lesion type, lesion length and the degree of calcification. Recently with the development of the percutaneous techniques and medical devices, success rate of peripheral interventions gradually increased and in the guidelines percutaneous interventions became first choice for the treatment for PAD [11].

Herein, patients with unsuccessful results had severely calcified long lesions. In these patients, surgical intervention may be recommendable as the first choice, however 28 of the successful interventions in our study was also performed in difficult i.e. TASC C and $D$ lesions. Thus, peripheral percutaneous interventions should be the first choice for experienced operators and surgery should be recommended as a bail-out strategy.

In this study, we found that most of the patients with moderate to severe claudication were totally asymptomatic after a mean of 11 months after the procedure and only $14.5 \%$ of the patients needed repeat revascularization. These results were comparable to previous studies $[9,10]$.

Complication rate of percutaneous peripheral interventions has been found to be low in previous studies $[12,13,14]$. We encountered only one serious complication after the procedure. This patient who had TASC-D lesion, diabetes mellitus and heart failure died due to contrast nephropathy. As a result, we may recommend that co-morbidities like diabetes mellitus, older age, heart failure should be taken into account while continuing a difficult percutaneous procedure.

The most common problem in the follow-up period in these patients is the recurrence of symptoms due to restenosis and new lesion development. Several parameters play role in these recurrences. Common patient related etiologies are smoking, uncontrolled diabetes mellitus, drug cessation. Some lesion related etiologies like dissection, calcification and residual lesion may also result in increased restenosis rates. In the literature DUSG and CTA are usually recommended for the follow up of patients after intervention [15]. CTA has been found to be correlated well with conventional peripheral angiography in several studies [16]. In this study among 9 patients who were found to have a significant lesion in CTA and underwent conventional angiography, all of them needed reintervention either percutaneous or surgically.

\section{LIMITATIONS}

The most important limitation of this single center retrospective study is the absence of control group who were only treated medically and a group who underwent surgical intervention to compare the 
results with percutaneous intervention patients. Besides, a relatively low number of patient enrollment is another limitation.

\section{CONCLUSIONS}

Peripheral interventions for SFA total occlusions are being performed successfully in experienced centers with low complication rates as the first treatment strategy in PAD. Herein, we have presented our patients who underwent successful PTA and/or stenting procedure with high success and low complication rates. Peripheral interventions should be the first choice for SFA total occlusions in experienced centers.

\section{CONFLICT of INTEREST}

The authors report no relationships that could be construed as a conflict of interest.

\section{reo REFERENCES Cem}

[1] Shah AM, Banerjee T, Mukherjee D. Coronary, peripheral and cerebrovascular disease: a complex relationship. Journal of the Indian Medical Association 2010; 108: 292-96.

[2]Tadros RO, Vouyouka AG, Ting W, et al. A Review of Superficial Femoral Artery Angioplasty and Stenting. J Vasc Med Surg 2015;3:1-5.

[3] Nadal LL, Cynamon J, Lipsitz EC, et al. Subintimal angioplasty for chronic arterial occlusions. Tech Vasc Interv Radiol 2004; 7,16-22.

[4]Dotter C.T, Judkins MP. Transluminal Treatment of Arteriosclerotic Obstruction. Description of A New Technic and A Preliminary Report of Its Application. Circulation 1964; 30:654-70.

[5] Norgren L, Hiatt WR, Dormandy JA, et al. TASC II Working Group: Inter-society consensus for the management of peripheral arterial disease (TASC II). J Vasc Surg 2007; 45, S5-S67.

[6] Setacci C, de Donato G, Teraa M, et al. Chapter IV: treatment of critical limb ischaemia [Review]. Eur J Vasc Endovasc Surg 42: S43-59.

[7]Norgren L, Hiatt WR, Dormandy JA, et al. Inter-Society Consensus for the Management of Peripheral Arterial Disease (TASC II). Eur J Vasc Endovasc Surg 2007; 33:S1-75.

[8]Carman T, Fernandez BB Jr. A primary care approach to the patient with claudication. Am Fam Physician 2000; 61:1027-34. [9]Duda SH, Pusich B, Richter G, et al. Sirolimus-eluting stents for the treatment of obstructive superficial femoral artery disease: six-month results. Circulation 2002; 106:1505-9.

[10]Duda SH, Bosiers M, Lammer J, et al. Sirolimus-eluting versus bare nitinol stent for obstructive superficial femoral artery disease: the SIROCCO II trial. J Vasc Interv Radiol 2005; 16:331-8. [11]Marie D, Gornik HL, Barrett C, et al. 2016 AHA/ACC Guideline on the Management of Patients with Lower Extremity Peripheral Artery Disease: Executive Summary. A Report of the American College of Cardiology/American Heart Association Task Force on Clinical Practice Guidelines. J Am Coll Cardiol 2017; 69:1465-1508.

[12] Baum S, Pentecost MD. Abram's Angiography. Interventional Radiology. 2nd Ed. Philedelphia: Lipincott Williams \& Wilkins.2006; 329-47.

[13] Pentecost MJ, Criqui MH, Dorros G, et al. Guidelines for peripheral percutaneous transluminal angioplasty of the abdominal aorta and lower extremity vessels. A statement for health professionals from a special writing group of the Councils on Cardiovascular Radiology, Arteriosclerosis, Cardio-Thoracic and Vascular Surgery, Clinical Cardiology, and Epidemiology and Prevention, the American Heart Association. Circulation 1994; 89:511-31.

[14]Valji K. Vascular and Interventional Radiology. 2nd Ed. Philedelphia: Elsevier. 2006; 34-36.

[15]Kawarada O, Higashimori A, Noguchi M, et al. Duplex criteria for instent restenosis in the superficial femoral artery. Catheter Cardiovasc Interv 2013; 281, E199-205.

[16] Itoga NK, Kim T, Sailer AM, et al, Lower extremity computed tomography angiography can help predict technical success of endovascular revascularization in the superficial femoral and popliteal artery. J Vasc Surg. 2017; 11, S0741-0748. 